\title{
How big is the bioeconomy?
}

\section{The Battelle/BIO report on the US bioeconomy is too inclusive in some places and too exclusive in others.}

\author{
Q: What's rich and lies at the heart of the US bioscience industry? \\ A: Thousands of highly paid corporate lawyers (jobs that should be included the \\ next time Battelle/BIO compile their report on US bioscience jobs)!
}

A ccording to nonprofit R\&D organization Battelle and trade association the Biotechnology Industry Organization (BIO), in the past decade US bioscience companies created nearly 111,000 new, high-paying jobs. These high-paying jobs are tallied in a new report entitled State Bioscience: Jobs, Investments and Innovation 2014, which now counts 1.62 million people working across 73,000 individual business establishments in the bioscience economy. The Battelle and BIO report, released at the annual BIO International Convention, reckons that the bioscience industry weathered the recession much better than other sectors of the US economy, expanding its economic output $17 \%$ since 2007, twice the average increase in the rest of the private sector.

How can this growth in economic output and high-paying jobs be reconciled with the thousands of R\&D personnel layoffs and restructuring that have been witnessed in the biopharmaceutical sector in recent years? The answer is that bioscience, according to BIO and Battelle, is spread significantly more broadly throughout the US economy than just biopharmaceuticals.

Battelle and BIO divide the bioeconomy into five broad sectors: "Agricultural Feedstock and Chemicals" (which includes industrial biotech), "Drugs and Pharmaceuticals," "Medical Devices and Equipment," "Research, Testing and Medical Laboratories" and "Bioscience-related Distribution." They recognize that there has been shrinkage in the core sectors of drug development and agbio. Indeed, pharma employment is down by nearly $11 \%$ since 2001 ; jobs in the agriculture and feedstock industries down $1.5 \%$. But those sectors represent fewer than $23 \%$ of the bioscience jobs identified by Battelle and BIO.

Instead, most of the job growth has occurred in the other three sectors: medical devices, businesses involved in the distribution of bioscience products, and research, clinical and manufacturing service providers. In the decade since 2001 , these grew by 349,000 jobs (up 1.5\%), 442,000 jobs (up 6.3\%) and 468,000 jobs (up 28.1\%), respectively.

Some of the Battelle/BIO definitions for these sectors are fairly loose; for example, Agricultural Feedstock and Chemicals includes any firm engaged in agricultural production and processing, organic chemical manufacturing and fertilizer manufacturing. Making fertilizers, it could be argued, is more the domain of the chemical industry than the biotech industry.

Similarly, the US Department of Labor definition for the medical device sector, adopted by Battelle and BIO, includes manufacturers of clamps, canulae and bone drills as well as syringes, knives and medical thermometers. It is relatively easy to accept that fabricators of amino acid analyzers belong in innovative biology; much harder to say the same for, say, makers of particle beam excitation instruments or refractometers.
In the Bioscience-related Distribution group, businesses captured include wholesalers of hospital furniture, crutches, dressings, hearing aids, medical glassware and whirlpool baths. Highly paid crutch craftsmen and innovative whirlpool designers are hardly the first people that come to mind when one thinks of innovative bioscience.

And whereas the Medical Laboratories category is definitely on the money when it comes to the importance of biology, it is less clear that such largely routine activities are really a product of the innovation ecosystem, rather than a continuation of the need for a healthcare system to monitor illness.

What seems particularly remiss, however, is that Battelle/BIO, with all their scraping around for inclusivity, have failed to include many more obviously related job categories in the bioscience cause. For example, the report tallies up the number of bioscience patents-these nearly doubled between 2009 and 2013-but does not enumerate bioscience patent lawyers. It notes the gradual increase in venture capital spending, but does not count up venture investors (perhaps because the numbers of these elite financial gatekeepers would not inflate the total substantially), let alone startup banks, foundations and family offices that participate in private sector financing.

It is even more difficult to fathom why they would not have claimed a proportion of the nearly 300,000 people who work in securities brokerages or of the 350,000 people who work in health and medical insurance, all of whose livelihoods are surely much more closely dependent on innovative biology than the folks who weld wheelchairs, forge dental amalgam or fashion state-of-the-art whirlpools.

In the same vein, why not include the increasing number of jobs and bureaucrats in the regulatory and reimbursement agencies that are needed to oversee the provision of bioscience products? It is clear that the move toward health technology assessments will require a growth in expertise in assessing the impact and value of new approvals. And as the medical paradigm moves toward more preventative and predictive approaches, there will be opportunities for those who oversee and/or handle biomedical data and for regulators assessing the cost/benefits of companion diagnostics and monitoring of biometric data.

So Battelle and BIO have missed a trick. In apparently not counting the lawyers, advisors, foreign and regional direct investment strategists and operatives, tax advisors, analysts, independent public relations specialists and management consultants, they have underestimated the overall size of the bioscience economy. And this journal would venture that the number of people they have excluded outstrips the personnel in their existing five categories whose relevance to the bioscience economy is debatable.

What is most surprising about this omission is that BIO should know better. After all, lawyers, advisors, consultants and money men are just the kind of highly paid people who loyally turn up to its annual industry jamboree, the BIO International Convention, year after year. 